\title{
THERMOSPHERIC COMPOSITION CHANGES SEEN DURING A GEOMAGNETIC STORM
}

\author{
A. G. Burns, * T. L. Killeen*,*** and R. G. Roble** \\ * Space Physics Research Laboratory, Department of Oceanic and \\ Atmospheric Sciences, University of Michigan, Ann Arbor, \\ MI 48109-2143, U.S.A. \\ ** High Altitude Observatory, National Center of Atmospheric Research, \\ P.O. Box 3000, Boulder, CO 80307, U.S.A. \\ *** Also a visiting scientist at the High Altutude Observatory, National Center \\ for Atmospheric Research, Boulder, CO 80307, U.S.A.†
}

\begin{abstract}
The largest magnitude winds observed using the instruments on board the Dynamics Explorer 2 (DE-2) satellite were measured during the large geomagnetic storm that occurred on the $24^{\text {th }}$ of November 1982 . Neutral temperatures exceeded $2000 \mathrm{~K}$ during this storm, and these high temperatures, combined with the very large observed winds and the very full instrumental coverage available in both hemispheres, make it a unique event to study. In this paper we present results obtained using these DE-2 data and a time dependent simulation of the event made using the National Center for Atmospheric Research Thermosphere/Ionosphere General Circulation Model (NCAR-TIGCM). In general, the agreement between model calculations and the data is very good, implying that most of the important physical processes controlling the energetics and dynamics of the thermosphere are reasonably well represented in the model. The modelled summer hemisphere changes in the mass mixing ratio of $\mathrm{N}_{2}\left(\Psi_{\mathrm{N} 2}\right)$ are in very good agreement w1th the DE-2 data, and the overall global pattern of $\Psi_{\mathrm{N} 2}$ in the model is also in good agreement with the averaged data in both hemispheres. This agreement allows us to study the physical processes occurring in the model with confidence that they are the same as those occurnng in the "real" thermosphere. This short paper describes moiel-expenment comparisons for the November 24, 1992 geomagnetic storm, but does not include the processes reponsible for these changes. A full description of them: $: 3$ avaliable in the set of papers $/ 1,2,3,4 /$
\end{abstract}

\section{INTRODUCTION}

The study of the changes in neutral composition that result from geomagnetic storms has contunued for a relatively long time. For example, Duncan /5/ attributed the observed high-latitude decrease in electron densities during geomagnetic storms to changes in neutral composition. Satellite measurements have enabled us to gain a greater understanding of the morphology of these changes, particularly in the region above $250 \mathrm{~km}$ In partıcular, Prölss /6/ has presented a local time-lattude map of the observed neutral composition changes durng geomagnetic storms. A number of theoretical studies have been made to attempt to explain these changes which have inet with considerable success (e.g. $7,8,9,10 /)$. However, these studies have attempted to solve the problems associated with composition changes during geomagnetic storms in a one or two dimensional sense, whereas the problem is essentially a threedimensional one.

The two major TGCMs (Thermospheric General Curculation Models) presently in existence, the University College London (UCL) TGCM /11 and 12/ and the NCAR-TIGCM /13,14 and 15/, have the potential to solve some of the problems associated with geomagnetic storms, provided that they can predict thermospheric composition changes accurately. Until recently it was believed that they were not producing the required composition changes (e. g. $/ 16$, $17 /$, but new work has indicated that not only are reasonable predictions being made $/ 4,18 /$, but also that the two models are in quite good agreement $/ 18 /$. It is clear that these models have now reached the stage where detailed comparisons should be made with data, so that a better understanding of the processes involved in producing storm tume composition changes can be attained.

In this paper we discuss a study of the very large geomagnetic storm that occurred on the $24^{\text {th }}$ of November 1982. Excellent data quality was avalable from all the instruments on board the Dynamics Explorer 2 spacecraft durng this storm, including measurements of neutral composition, wind and temperatures, ion winds and ion temperatures, and electron densities and temperatures. Neutral composition variations cannot be considered in isolation from the other state vanables of the thermosphere, and a greater understanding of neutral composition changes is best ganed by using as many different types of data as possible, combined with the most appropnate model. Such coverage is 
provided by the DE-2 data and by the NCAR-TIGCM for this tume period The geomagnetıc storm studied is described in more detal in the next section, which also includes a general comparison of model results with DE-2 data, and a specific comparison between these data and the model for one orbit The results of this work are summarized in the last section.

\section{DATA-MODEL COMPARISONS}

A very large geomagnetic storm occurred at about 1100 hours universal tume (UT) on day 328 of 1982 (see Figure la for the record of the $K_{p}$ index durng this period) The large event was preceded by 2 smaller storms in the previous two days, before which geomagnetıc activity had been predominantly moderate for a few days. The relatively short penod (10 - 11 hours) between the large event and the preceding smaller event means that long-lived thermosphenc compositional perturbations induced by the earlier geomagnetic activity may have affected the data associated with the later event. In this later event, which is the storm discussed here, $\mathrm{K}_{\mathrm{p}}$ reached values of $7^{+}$, and very strong geomagnetic activity ( $\mathrm{K}_{\mathrm{p}}$ greater than $7^{-}$) continued for the 15 hours after 1200 UT (the storm onset occurred at around 1100 UT). Data were also available about the interplanetary magnetic field (IMF) for this period. Bulk IMF speeds of over $800 \mathrm{~km} / \mathrm{s}$ were observed during this storm and the magnitude of the IMF exceeded $30 \mathrm{nT}$ at tumes The large values of these IMF parameters were associated with large potential drops across the polar cap, which in turn forced ion winds of more than $2000 \mathrm{~m} / \mathrm{s}$ and neutral winds in excess of $1200 \mathrm{~m} / \mathrm{s}$. These strong winds also led to large temperature increases as a result of frictional heatung (neutral temperatures exceeded $2000 \mathrm{~K}$ at tumes), and consequently large changes in neutral composition at high and middle latitudes

The NCAR-TGCM is a three-dimensional, tume-dependent model of the Earth's neutral upper atmosphere that is run on the CRAY-XMP and YMP computers at NCAR. The model uses a finite-differencing technique to obtain tumedependent solutions for the coupled, non-linear equations of hydrodynamics, thermodynamics and continuity of the neutral gas $/ 13,14 /$ and for the coupling between the dynamics and the composition /14/. The new TIGCM with a coupled 1onosphere and a self-consistent aeronomic scheme has been developed recently by $/ 15 /$. The simulation used in this study was a time-dependent study, appropriate for the geophysical conditions that existed on November 24 , 1982, which was made by specifying the cross-cap potential and hemisphenc power using algorithms developed by Drs. P Reiff and B Emery, $B_{y}$ data from NSSDC and F 10.7 data from Ottawa.
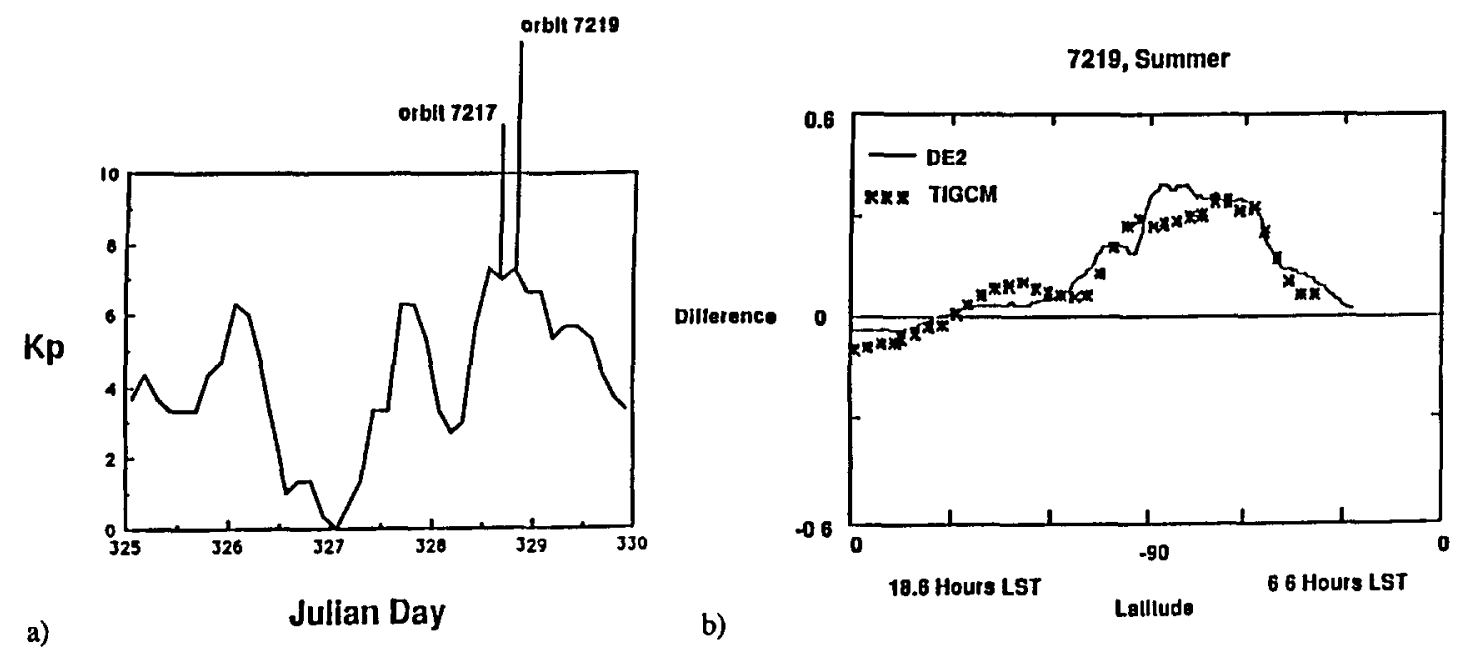

Fig. 1. a) $K_{p}$ values for the period prior to and including the storm on the $24^{\text {th }}$ of November b) $A$ companson of $\Psi_{\mathrm{N} 2}$ changes for DE-2 storm tume data compared with the quiet time MSIS case and for the equivalent orbit through the NCAR-TIGCM simulation in storm and quiet times. The data and the model simulations are for DE-2 orbit 7219 , which occurred at about 1900 hours on the $24^{\text {th }}$ of November. The magnetic pole projection is located about 10 degrees from the geographical pole on the dawn side.

A comparison has been made between the $\Psi_{\mathrm{N} 2}$ changes from storm to quiet times predicted by the NCAR-TIGCM and those observed by the DE-2 satellite (the satellite data are compared with quiet tume MSIS - 86/19/values) during orbit 7219 , at about 1900 hours on the $24^{\text {th }}$ of November (Figure 1b). This figure 1 s for the summer (southern) hemisphere and the altutude of the satellite is between about $270 \mathrm{~km}$ and about $530 \mathrm{~km}$ (the latter occurs at low latitudes on the morning side of the auroral oval). An equivalent satellite trajectory has been run through the gridded model output fields, allowing a point by point companson to be made with the DE-2 data. The agreement between the model and the data is excellent at this time, w1th the peak in $\Psi_{\mathrm{N} 2}$ perturbations occurning in the region between about 70 degrees geographic latutude on the evening side of the auroral and 50 degrees on the morning side. The magnetic pole projection is displaced some 10 degrees to the morning side of the geographic pole at this universal time and this will influence the distribution of changes in $\Psi_{\mathrm{N} 2}$. Agreement is not perfect at these high latitude regions, primarily because of the difficulties of parameterizing the con convection pattern and the auroral precipitation. The NCAR- 
TIGCM also predicts a region of slight enhancements in $\Psi_{\mathrm{N} 2}$ in the middle latitudes in the evening hours. These enhancements represent remnants from the previous storm but they can not be seen in the DE- 2 data. Two explanations are apparent for this discrepancy: firstly, the auroral inputs used for the previous storm may have been too large and the composition changes may have been over predicted, or, secondly, the compositional recovery rate in the TIGCM may be too slow, leaving a larger "fossil" remnant $\Psi_{\mathrm{N} 2}$ remnant than that which really occurs. We are currently studying this problem as part of a larger effort to understand post-storm compositional and thermal recovery
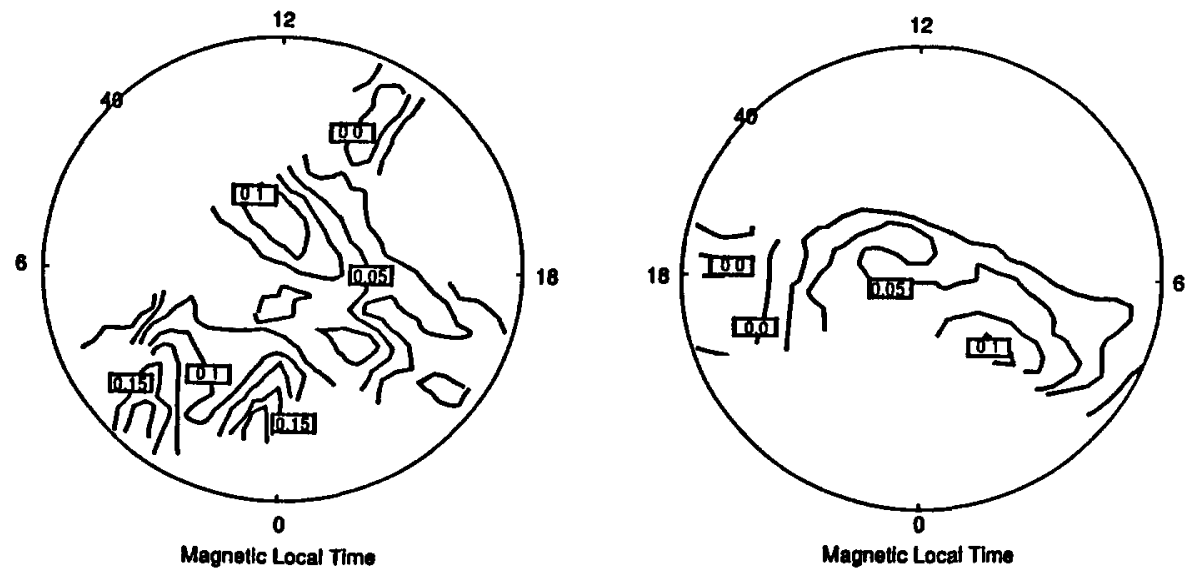

Fig. 3. Differences between the averages of DE-2 $\Psi_{\mathrm{N} 2}$ when $K_{p}>4^{+}$and when $K_{p}<4^{\circ}$ during the northern hemisphere winters of $1981 / 82$ and 1982/83. The projections are in geomagnetuc coordinates and extend from 40 degrees to the pole. The angular axas is in magnetic local time, and the altutude is 300 $\mathrm{km}$. The left hand polar diagram represents the southern hemisphere changes at this tume and the right hand polar diagram represents the winter hemisphere changes.

A more complete understanding of the storm time compositional response to geomagnetuc forcing can be ganed by comparing the averaged DE-2 compositional structure at times of high geomagnetic activity with the modelled compositional structure at similar times. Figure 3 shows the DE-2 measured differences between the averaged $\Psi_{\mathrm{N} 2}$ at high geomagnetic activity $\left(\mathrm{K}_{\mathrm{p}}>4^{+}\right)$and the averaged $\Psi_{\mathrm{N} 2}$ at low geomagnetuc activity $\left(\mathrm{K}_{\mathrm{p}}<40\right)$ for both the summer and winter hemispheres at solar maximum. One major feature that is seen in both hemispheres is that there is little enhancement in $\Psi_{\mathrm{N} 2}$ on the dayside and evening side of the auroral oval. In fact, there 1s a decrease in $\Psi_{\mathrm{N} 2}$ on the evening side of the auroral oval /4/ in the northem (winter) hemisphere at middle latutudes. Also, the area of stormtume enhanced $\Psi_{\mathrm{N} 2}$ perturbation is very much offset towards the morning side of the auroral oval. Of particular note is the very distunctive pattern of enhancement in the summer hemisphere, whereby one tongue of strong enhancement extends towards lower lattudes at magnetic local midnight and another towards lower latitudes at a magnetic local tume of about 300 hours. These averaged patterns should be treated with a little caution, however, as they are an amalgamation of data from a number of storms with very different intensities. They tend to be more representatuve of smaller storms rather than larger ones, as these occur more frequently. Another feature of interest is that storm-related $\Psi_{\mathrm{N} 2}$ enhancements extend to lower latutudes in the summer hemisphere than in the winter hemisphere (also see $/ 21$ ), and that $\Psi_{\mathrm{N} 2}$ does not show larger changes in the winter hemisphere than in the summer hemisphere, unlike the $\mathrm{N}_{2} / \mathrm{O}$ ratio $/ 20 \%$
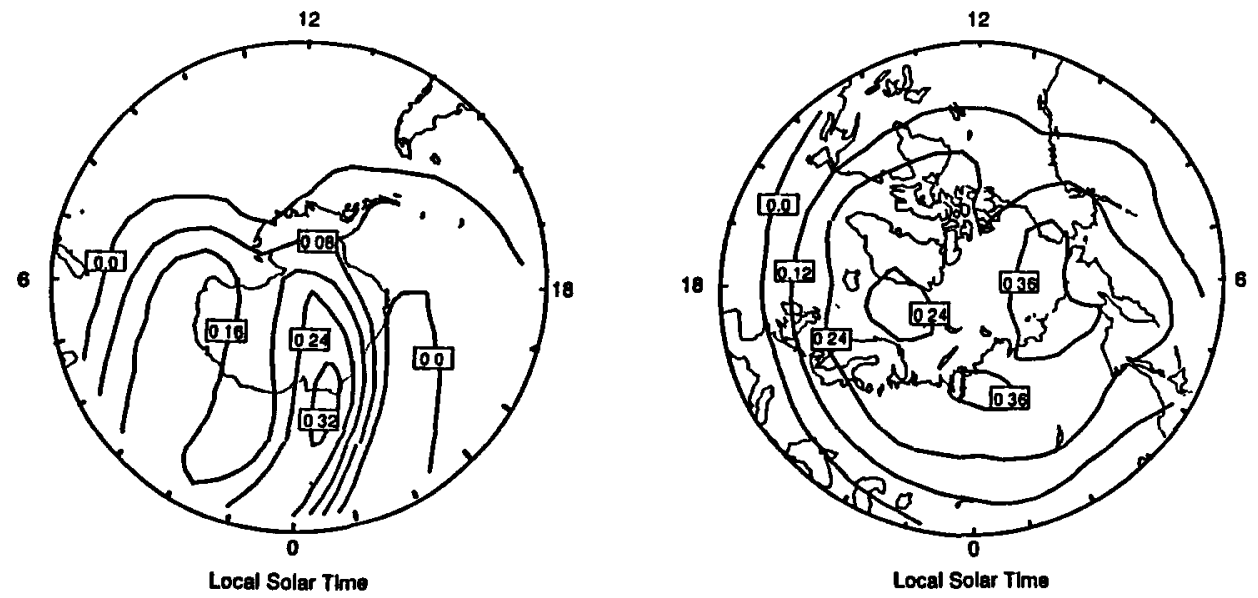

Fig. 4. Differences between $\Psi_{\mathrm{N} 2}$ for the NCAR-TIGCM simulation at 1900 hours UT on the $24^{\text {th }}$ of November 1982 and the equivalent simulation at times of moderate geomagnetuc activity. The results are in geographic coordinates for the $\mathrm{Z}=2$ pressure surface $(\sim 350 \mathrm{~km})$. 
Figure 4 shows the NCAR-TIGCM predictions of changes in $\Psi_{\mathrm{N} 2}$ for the very large storm that was described earlier. The modelled enhancements in $\Psi_{\mathrm{N} 2}$ are larger than those seen in the data considered in the previous paragraph, primarily because of the large magnitude of this storm. The overall pattern of $\Psi_{\mathrm{N} 2}$ changes is very similar to that of the data. for example, the southern (summer) hemisphere has the two tongues of enhancement at local midnight and 300 hours local solar time, with an area of smaller enhancement in between. It is harder to make comparisons in winter because the data are more sparse, but the overall pattern seems very similar, with the largest enhancements being seen in the early morning hours near the auroral oval. It is unclear from this diagram whether the model is predictung a larger area of enhancement in the summer hemisphere than in the winter hemisphere as is seen in the data, but this feature does become apparent when global plots of mixing ratio change are considered. Even within the area of enhancement there are striking differences between the two hemispheres, with the large enhancements tending to be restricted to the area near the auroral oval in the winter hemisphere, but extending far equatorward in the summer hemisphere on the early morning side of the auroral oval The dayside enhancements equatorward of the auroral oval in the winter hemisphere represent remnants of the previous storm, rather than effects due to this penod of enhanced activity.

\section{CONCLUSIONS}

We have conducted an investigation into the compositional changes associated with the very large geomagnetc storm that occurred on the $24^{\text {th }}$ of November 1982 using DE-2 data and a simulation of the event that was made using the NCAR-TIGCM The large changes in the thermosphere and lonosphere that occurred during this storm make it a very interesting event to study. A point by point comparison was made by running a simulated satellite trajectory through the model, and the agreement between the model and the data was found to be excellent at times. A morphological companson has also been made between this model simulation and the averaged DE-2 values of the changes that occur dunng geomagnetic storms The major features seen in the data are also reproduced by the model: the differences between the summer and winter patterns are well represented, including the smaller size of the area of enhancement in the winter hemisphere, the curious twin tongues of enhancement extending from the auroral oval towards local midnight and 300 hours local time in the summer hemisphere appearin both; the general tendency for the enhancements to occur in the early morning hours is seen and the lack of enhancements and possible reductions of $\Psi_{\mathrm{N} 2}$ on the dayside and evening side of the auroral oval appear in both the model and the data. These results give us confidence that we can investigate the physical processes responsible for composition changes during a geomagnetic storm using the NCAR-TIGCM and the diagnostic processor discussed in $/ 1,2,3$ and $4 /$, with reasonable confidence that these processes are reasonably representative of those that are occurring in the real thermosphere. The other major conclusion that can be drawn from this study is that more physical insight can be gained when data are used in conjunction with modelling efforts than is avallable when etther is used separately.

\section{ACKNOWLEDGEMENTS}

The work was supported by the NSF grant ATM-8918476 and by the NASA grant NAG5-465 to the University of Michigan The authors wish to acknowledge useful discussions with Drs. P. Reiff and B. Emery.

\section{REFERENCES}

1. T. L. Killeen and R. G. Roble, $J$ Geophys Res , 89, 7509-7522, 1984.

2. T. L. Killeen and R. G Roble, J Geophys Res., 91, 11291-11307, 1986.

3 A. G. Burns, T. L. Killeen and R. G. Roble, J Geophys. Res., 94, 3670-3686, 1989.

4 A. G. Burns, T. L. Killeen, G. R Cangnan and R. G. Roble, submitted to J. Geophys Res , 1990.

5. R. A. Duncan, $J$ Atmos Terr Phys, 31, 59-70, 1969.

6. G. W. Pròlss, J Geophys Res 86, 2385-2396, 1981.

7. P. B Hays, R A. Jones and M. H Rees, Planet Space $S C l, 21,559-573,1973$.

8. H. G. Mayr and H. Volland, $J$ Geophys Res , 78, 2251-2264, 1973.

9. H. G Mayr and A E Hedin, $J$ Geophys Res , 82, 1227-1234, 1977.

10. H G. Mayr,and H. Trnks, Planet Space Scl , 25, 607-613, 1977.

11 T J. Fuller-Rowell and D. Rees, $J$ Atmos SCl, 37, 2545-2567, 1980

12. T. J Fuller-Rowell, and D. Rees, Planet Space Scl, 31, 1209-1222, 1983.

13 R E Dickinson, E. C Ridley and R G. Roble, J Atmos Scl, 41, 205-219, 1984.

15. R. G. Roble, E. C Ridley, A. D Richmond and R. E Dickinson, Geophys Res Lett, 15, 1325-1328, 1988

16 H Rishbeth, R. Gordon, D. Rees and T. J. Fuller-Rowell, Planet Space Sci, 33, 1283-1301, 1985.

17. H. Rushbeth,T. J. Fuller-Rowell and A S. Rodger, Phys Scripta , 36, 327, 1987.

18. T. J. Fuller-Rowell, D. Rees, H Rishbeth, A G Burns, T L. Killeen and R. G. Roble, J Atmos Terr Phys, in press 1990

19 A. E Hedin, J Geophys Res , 92, 4649-4662, 1987.

20 G W. Prolss, Rev Geophys Space Phys, 18, 183-202, 1980. 